\title{
Advanced Electrolyte/Additive for Lithium-Ion Batteries with Silicon Anode
}

\author{
Shuo Zhang, Meinan He, Chi-Cheung Su, Zhengcheng Zhang* \\ Chemical Science and Engineering Division \\ Argonne National Laboratory \\ Argonne, IL 60439, USA
}

\begin{abstract}
State-of-the-art lithium-ion batteries (LIBs) are based on a lithium transition metal oxide cathode, a graphite anode and a non-aqueous carbonate electrolyte. To further increase the energy and power density of LIBs, silicon anodes have been intensively explored due to their high theoretical capacity, low operation potential, and low cost. However, the main challenges for Si anode are the large volume change during lithiation/delithiation process and the instability of the solid-electrolyte-interphase associated with this process. Recently, significant progress has been achieved via advanced material fabrication technologies and rational electrolyte design in terms of improving the Coulombic efficiency and capacity retention. In this paper, new developments in advanced electrolyte and additive for LIBs with Si anode were systematically reviewed, and perspectives over future research are suggested at the end of the review.
\end{abstract}

\footnotetext{
* To whom correspondence should be addressed. E-mail: zzhang@anl.gov (Z. Z.).
} 


\section{Introduction}

Commercially available lithium-ion batteries (LIBs) for consumer electronics and electric vehicles are based on a lithium transition metal oxide cathode and a graphite anode with an electrolyte, either a solution of a lithium salt dissolved in an organic solvent or the same solution trapped in a gel. ${ }^{1}$ Currently, development of battery technology is rather imperative to accommodate applications demanding even higher energy density and power density, such as electric vehicles ${ }^{2-3}$. For this purpose, great advances have been made in both high-energy cathode materials ${ }^{4}$ and high-energy anode materials ${ }^{5}$. Development of cathode materials progressed dramatically by our colleagues at Argonne National Laboratory ${ }^{6}$. On the anode side, siliconbased materials emerged as a super high-capacity candidate $\left(4008 \mathrm{mAh} / \mathrm{g}\right.$ for $\mathrm{Li}_{22} \mathrm{Si}_{5}, 3579$ $\mathrm{mAh} / \mathrm{g}$ for $\mathrm{Li}_{13} \mathrm{Si}_{4}$ ) (Figure 1) for LIBs. ${ }^{7}$ Other alloys ${ }^{8-9}$ and metal oxides ${ }^{10}$ as new anode materials also witnessed great promise. However, due to their distinctive characteristics from the conventional carbonaceous anode, these anode materials have raised additional challenges for battery electrolytes and additives. ${ }^{11-12}$ 


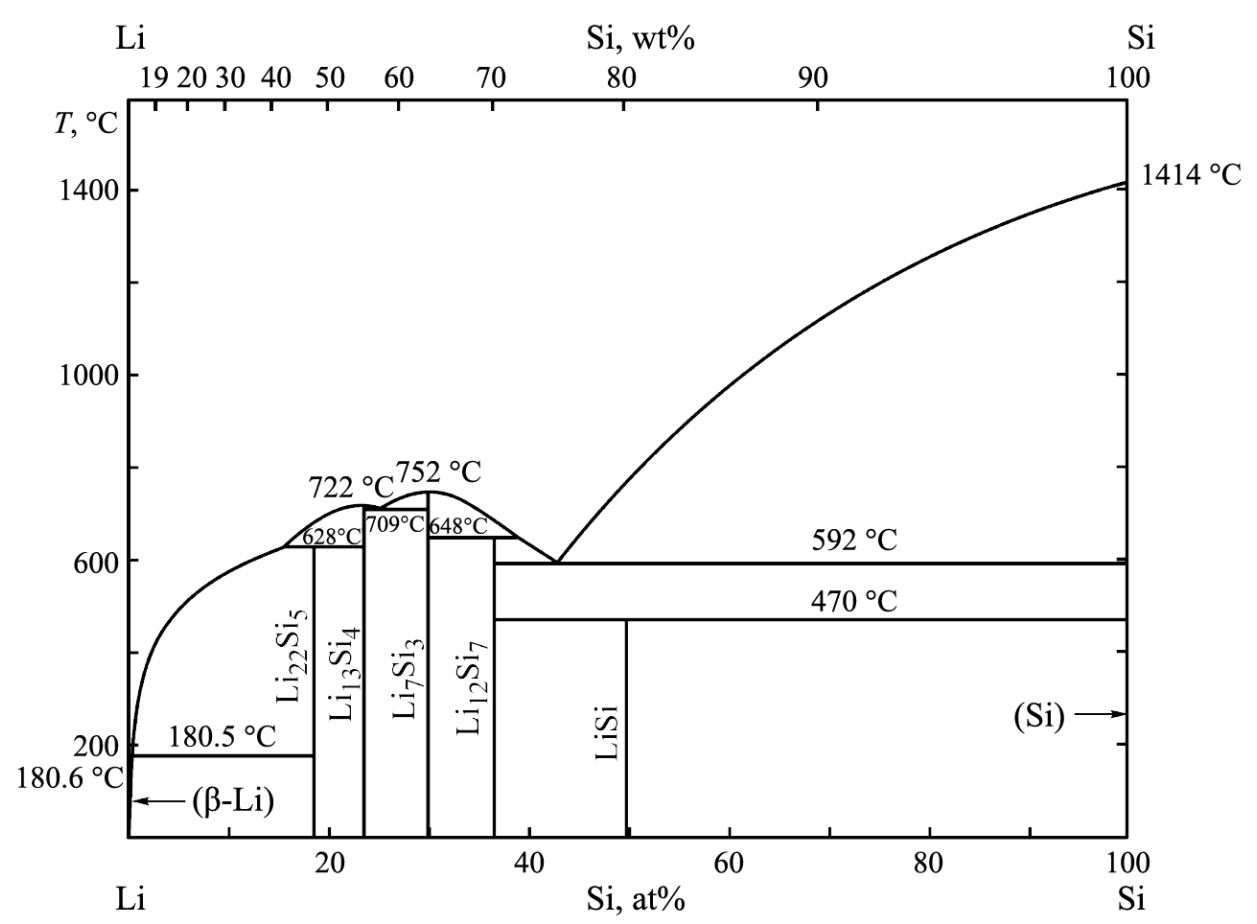

Figure 1. Phase diagram of the Li-Si binary system. (Reproduced with permission of Springer ${ }^{3}$ ).

Two major issues were identified to be critical to realize the application of $\mathrm{Si}$ anode in LIBs: large volume expansion and shrinkage of Si particles during lithiation and delithiation and the instability and high resistance of solid-electrolyte-interphase (SEI) due to the repeated construction and destruction in the presence of the conventional electrolytes and additives, leading to continuous electrolyte decomposition. ${ }^{13}$

The dramatic volume expansion ( $>300 \%$ when completely lithiated) remains a challenge for LIBs with Si anode. Cracking of active material and loss of electrical conduction paths is inevitable due to the large volume change of the active silicon phase during the insertion and extraction of lithium. The reductive reaction of electrolytes and additives with the components of the native layer $\left(\mathrm{SiO}_{\mathrm{x}}\right)$ and silanol $(\mathrm{Si}-\mathrm{OH})$ involves lithium species during the repeated lithiation process, causing active lithium loss and fast capacity fade. 
A stable SEI is indispensable for the Si anode to afford extended charge and discharge cycles to protect electrolyte from continuous degradation and subsequent depletion. ${ }^{14}$ Despite the complexity of SEI, the relative performance of LIBs is highly dependent on electrolyte composition, impurity concentration, presence of protective additives, charge/discharge conditions etc. Therefore, the insight into the decomposition mechanism of electrolytes and additives is complicated by a number of contributing factors ranging from formulation to operation conditions, and challenged by the sensitivity of varied characterization techniques. ${ }^{14}$

A variety of electrolytes/additives have been investigated in the last decade for silicon anode. Carbonate based electrolyte is still the main stream of the research with a couple of emerging systems. Electrolyte additive plays a significant role in passivating the Si/electrolyte interphase during the initial lithiation process. Fluoroethylene carbonate (FEC) is the most effective additive for extended cycle life of Si anode. Other additives including carbonates, silanes, ethers, carboxylic anhydrides, and organoboron compounds have been also developed and reviewed in the paper.

\section{Carbonate electrolytes}


(a)
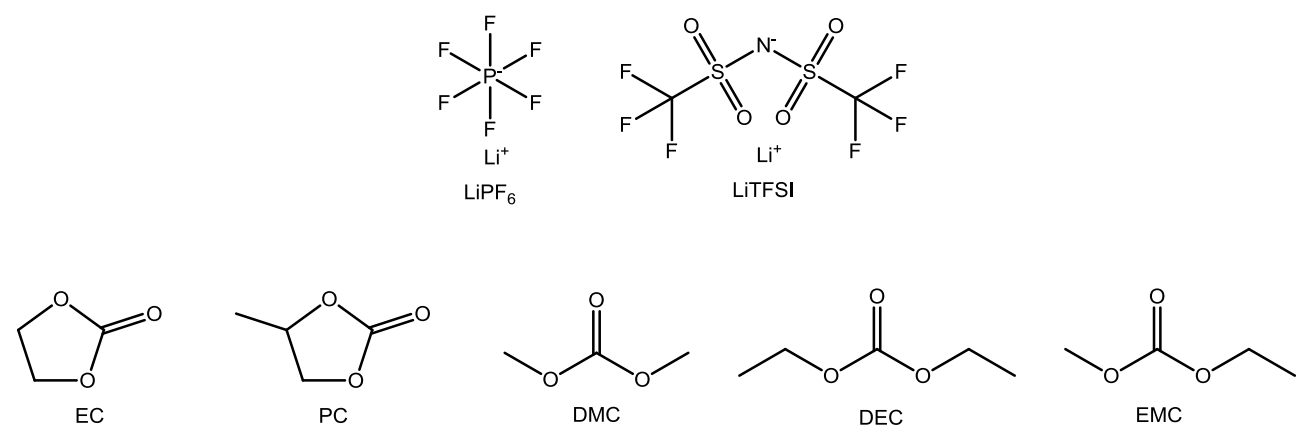

(b)

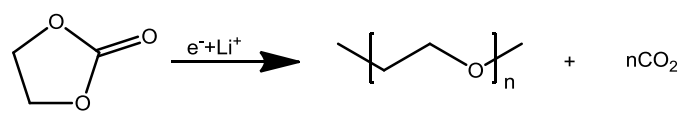<smiles>CCOC(=O)O</smiles>

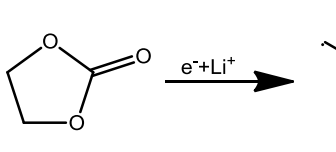<smiles>CCOC(=O)O</smiles>

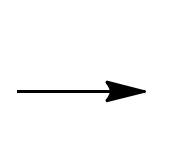<smiles></smiles><smiles>O=C(O)OCCCCOC(=O)O</smiles>

(c)

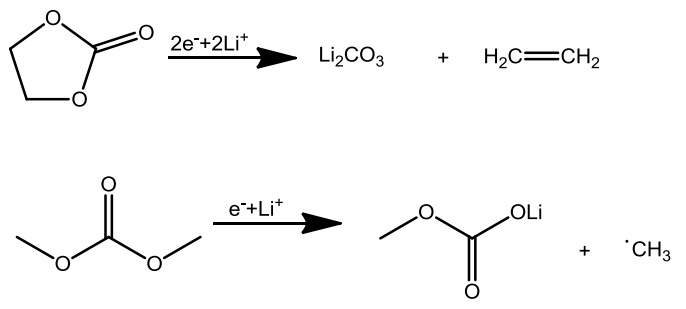<smiles>C=C[C@@H]1OCCOC1=O</smiles>

Figure 2. (a) Chemical structure of lithium salt and carbonate solvents and (b) ethylene carbonate and (c) dimethyl carbonate reduction reactions on the surface of $\mathrm{Si}$ anode (oneelectron and two-electron reduction. ${ }^{14}$ (Reproduced with permission from American Chemical Society).

The conventional electrolytes for LIBs are liquid solutions of lithium salts in mixtures of aprotic organic solvents, such as lithium hexafluorophosphate $\left(\mathrm{LiPF}_{6}\right)$ or lithium 
bis(trifluoromethanesulfonyl)imide (LiTFSI) in ethylene carbonate (EC), dimethyl carbonate (DMC), diethyl carbonate (DEC), or mixture of the above (Figure 2 (a)). The electrochemical reactions of EC and DMC solvents during the lithiation process were theoretically calculated by density function theory (DFT) and experimentally revealed by ${ }^{1} \mathrm{H},{ }^{19} \mathrm{~F}{ }^{7} \mathrm{Li}$, and ${ }^{13} \mathrm{C}$ solid-sate nuclear magnetic resonance spectroscopy (ssNMR). The most abundant products were identified to be poly(ethylene oxide)-type species with one plausible reaction releasing carbon dioxide. The proposed mechanisms for the one-electron and two-electron reductive decomposition of EC and DMC were shown in Figure 2(b) and 2(c). ${ }^{14}$ These results were consistent with the prior analysis performed with X-ray photoelectron spectroscopy (XPS). ${ }^{13}$ To develop stable electrolyte, noncarbonate based electrolytes are currently sought and actively investigated. ${ }^{15}$

\section{Ionic liquid electrolytes}

Ionic liquids (ILs) based electrolyte has been reviewed for LIBs with graphite anode and other energy storage systems in prior art. ${ }^{1,16}$ Ionic liquid electrolyte are room-temperature molten salts and composed mostly of organic ions that may undergo almost unlimited structural variations. ${ }^{1}$ Beyond its chemical and electrochemical inertness at the interface of the electrode/electrolyte, ILs is thermally stable and non-flammable which renders the improved safety property, a critical technical challenge especially for the electric vehicle application. Typical cations and anions of the ILs investigated in LIBs with Si anode were summarized in Figure 3. 


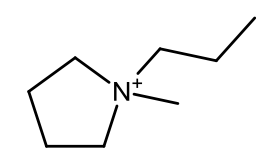

$\mathrm{PYR}_{13}$

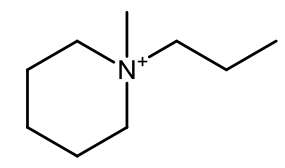

$\mathrm{PP}_{13}$

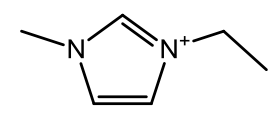

EMI

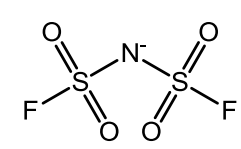

FSI

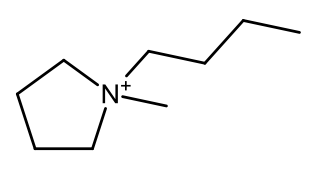

$\mathrm{PYR}_{14}$

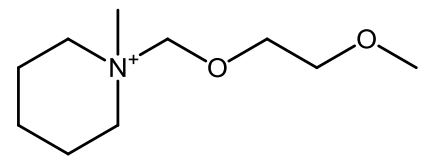

$\mathrm{PP}_{1 \mathrm{MEM}}$
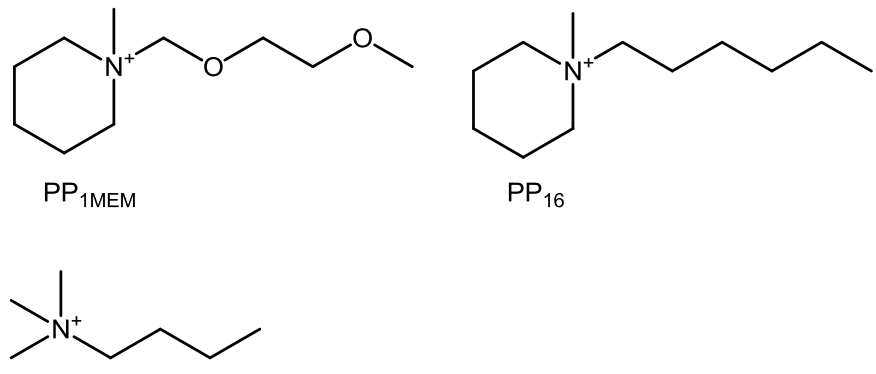

BTMA

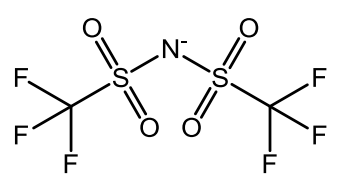

TFSI

Figure 3. Chemical structures of typical anions and cations used in ionic liquid electrolytes.

It was demonstrated that ILs electrolyte based on 1-methyl-1-propylpyrrolidinium ( $\left.\mathrm{PYR}_{13}\right)$ or 1methyl-1-butylpyrrolidinium $\left(\mathrm{PYR}_{14}\right)$ cation and TFSI anion cycled well in cells with lithium metal as an anode, offering a dramatic increase in energy density. ${ }^{17}$ The same electrolyte was also investigated with $60 \mathrm{~nm} \mathrm{Si-Cu}$ film electrode in a three-electrode configuration. A stable SEI layer was formed on the surface of the $\mathrm{Si}-\mathrm{Cu}$ film evidenced by ex-situ attenuated total reflection Fourier-transform infrared spectroscopy (ATR-FTIR) and XPS studies. ${ }^{18}$ The SEI layer is found to be composed of organic and inorganic compounds that are the decomposition products of $\mathrm{PYR}_{13}$ cation and TFSI anion, and effectively passivate the electrode surface during initial cycling. Formation of a stable SEI layer leads to an excellent capacity retention $98 \%$ of the maximum discharge capacity, delivering discharge capacities of $>1620 \mathrm{mAhg}^{-1}$ over 200 cycles. The data contribute to a basic understanding of SEI formation and composition responsible for 
the cycling performance of Si-based alloy anodes in ionic liquid electrolyte-based rechargeable lithium batteries. ${ }^{10}$

More recently, Piper et al. ${ }^{16}$ studied the $1.2 \mathrm{M} \mathrm{LiFSI}$ in PYR ${ }_{13}$ FSI and 0.6 M LiTFSI in $\mathrm{PYR}_{13}$ TFSI ionic liquid electrolytes on the Si-based nanocomposite electrode rather than thinfilm electrode. The cycling performances of the Li half cells were directly compared with the commercial EC/DEC (1.0 $\mathrm{M} \mathrm{LiPF}_{6}$ ) electrolyte, demonstrating the exceptional cycling stability of the nSi-cPAN anodes in FSI anion-based ILs and their unprecedented Coulombic efficiency (CE) of $99.97 \%$ in 200 cycles in the PYR13FSI system. The unparalleled CEs of the SiPYR13FSI system are attributed to the formation of a highly stable SEI by the decomposition product of FSI anion, which mitigates the continuous SEI formation experienced in organic electrolyte.

Superior cycling performance of $1.2 \mathrm{M}$ LiFSI in PYR ${ }_{13} \mathrm{FSI}$ was also obtained for $\mathrm{LiNi}_{1 / 3} \mathrm{Mn}_{1 / 3} \mathrm{Co}_{1 / 3} \mathrm{O}_{2} / \mathrm{Si}$ full-cells, attributed to the high half-cell CEs, with an average irreversible charge loss of just $0.076 \%$ for the first 100 cycles (Figure 4(a)) followed by negligible Li consumption, providing an average full-cell charge capacity of $110.98 \mathrm{mAh} \mathrm{g}^{-1}$ at a rate of $\mathrm{C} / 2$. To further investigate the SEI stability of the Si-PYR13FSI system, a full-cell was cycled for longevity with a brief rate study. Figure 4(b) depicts the nSi-cPAN/PYR13FSI (1.2 M LiFSI)/L333 cell run for 1,000 cycles delivering 107.33, 74.70 and $58.26 \mathrm{mAh} / \mathrm{g}$ at rates of $1 \mathrm{C}$, $4 \mathrm{C}$ and $6 \mathrm{C}$, respectively. 
(a)
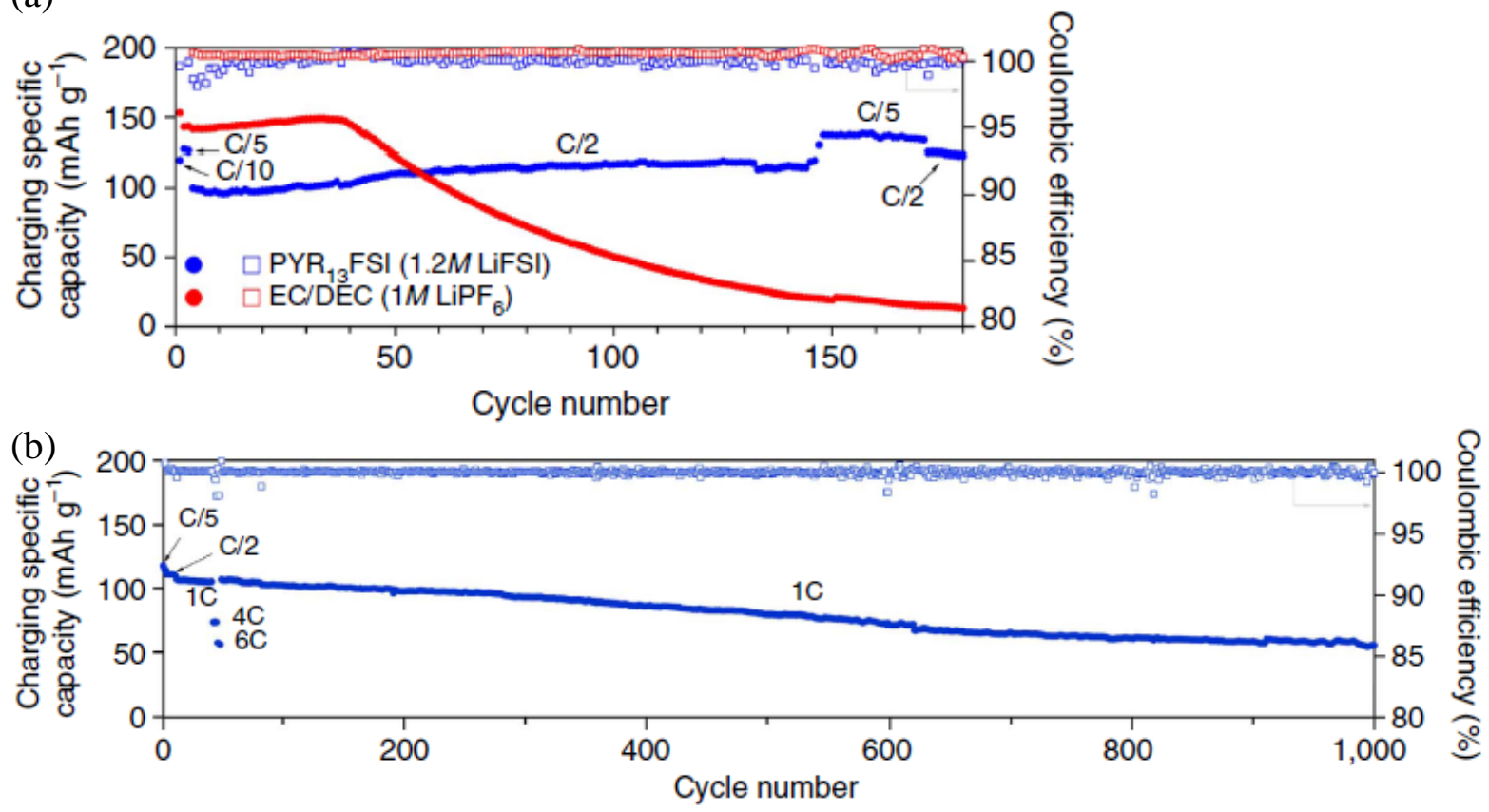

Figure 4. Full-cell electrochemical performance of Si-PAN/L333 with PYR $_{13} F S I$ versus EC/DEC electrolyte systems. (a) Specific charge capacities and coulombic efficiencies of $\mathrm{nSi}$ PAN/L333 full-cells assembled with PYR ${ }_{13}$ FSI (1.2M LiFSI) and conventional EC/DEC (1M $\mathrm{LiPF}_{6}$ ) electrolytes. (b) nSi-PAN/PYR ${ }_{13} \mathrm{FSI} / \mathrm{L} 333$ full-cell rate study and long-term cycling. Cycling was carried out at room temperature in 2032 coin-type half-cells operated between 2.0 and 4.15 V (versus Li/Li'). ${ }^{19}$ (Reproduced with permission from Nature Publishing Group)

As an analogue of pyrrolidinium, the piperidinium based ionic liquids was also studied in a full cell comprising of $\mathrm{LiCoO}_{2}$ cathode and $\mathrm{Si}$ anode. Preliminary studies on 1-methyl-1propylpiperidinium $\left(\mathrm{PP}_{13}\right)$ bis(trifluoromethylsufonyl)imide (TFSI) yielded $3000 \mathrm{mAh} / \mathrm{g}$ in halfcells and only suffered from moderate capacity fading. ${ }^{20}$ This discovery was followed by a 
comparative investigation performed with $\mathrm{PP}_{13} \mathrm{FSI}, \mathrm{PP}{ }_{13} \mathrm{TFSI}$, and imidazolium based ionic liquid EMIFSI and EMITFSI using $\mathrm{LaSi}_{2} / \mathrm{Si}$ composite anode. ${ }^{21}$ Despite of the improved performance of $\mathrm{LaSi}_{2} / \mathrm{Si}$ composite anode over neat $\mathrm{Si}$ anode, $\mathrm{PP}{ }_{13} \mathrm{FSI}$ was identified as the best among all the ILs, with discharge capacity of $800 \mathrm{mAh} / \mathrm{g}$ after 250 cycles. More studies were performed on effects of cation structures on the $\mathrm{Si}$ anode by introduction of hydrophilic and hydrophobic substituents onto the nitrogen center, e.g., 1-((2-methoxyethoxy)methyl)-1methylpiperidinium ( $\left.\mathrm{PP}_{1 \mathrm{MEM}}\right)$ and 1-hexyl-1-methylpiperidinium $\left(\mathrm{PP}_{16}\right)$, respectively. ${ }^{22}$ Raman analysis and electrochemical impedance measurements revealed that $\mathrm{PP}_{1 \mathrm{MEM}}$ cation played a role reducing the interaction between $\mathrm{Li}^{+}$and TFSI anions, and that $\mathrm{Li}$-ion transfer at the electrode-electrolyte interface in $\mathrm{PP}_{1 \mathrm{MEM}}$-TFSI was remarkably improved compared with $\mathrm{PP}_{16^{-}}$ TFSI. These results indicate that the excellent performances obtained in $\mathrm{PP}_{1 \mathrm{MEM}}-\mathrm{TFSI}$ originate from a smooth $\mathrm{Li}$-insertion into $\mathrm{Si}$ electrode. Functionalization of the cation structure is effective approach in improving the electrode performance.

Other ionic liquid electrolytes including imidazolium based and ammonium based were also investigated. The widely studied imidazolium ionic liquids are 1-ethyl-3-methylimidazolium (EMI) bis(fluorosulfonyl)imide (FSI) and EMITFSI in LIBs with Si composite anode. ${ }^{23}$ While ILs based on FSI anion offered reversible capacity for a Si composite anode without any solvent, ILs based on TFSI anion showed no reversible capacity at all. Chakrapani et al. reported that ILs based on butyltrimethylammonium (BTMA) cation and TFSI anion delivered higher discharge capacity for Si nanowire anode. ${ }^{24}$ Discharge capacity up to $2000 \mathrm{mAh} / \mathrm{g}$ was documented after 50 cycles with CE of $97 \%$. This discovery readdressed the significance of quaternary ammonium (QA) ionic liquids in LIBs with Si anode. 
Table 1 summarized and compared the electrochemical properties of all the ionic liquid electrolytes for lithium-ion battery with $\mathrm{Si}$ anode reported in the literature.

\section{Other electrolytes}

Polymer electrolytes are complexes formed by polymers capable of solvating ions of metal salts. The most representative examples are those involving polyethylene oxide (PEO), and lithium metal salts ( $\mathrm{LiX}$ with $\left.\mathrm{X}=\mathrm{PF}_{6}, \mathrm{TFSI}, \mathrm{ClO}_{4}\right) .{ }^{15}$ Although widely studied in LIBs with graphite anode, there are only few reports on polymer electrolyte for $\mathrm{Si}$ anode. Haruta et al. recently reported an oligomeric PEO electrolyte of tetraethylene glycol dimethyl ether complexed with LiTFSI. The complex shows high ionic conductivity and is capable of forming SEI in the presence of FEC on $\mathrm{Si}$ anode. $^{25}$

Due to their low ambient conductivity, PEO based polymer electrolytes have a limited application in LIBs. Alternative, more conductive gel-type polymer electrolytes, GPEs, appear to be a promising choice. Bok et al. developed a GPE via thermally initiated free-radical crosslinking reaction of ethoxylated trimethylolpropane triacrylate (ETPTA) in the presence of

EC/DEC containing $10 \mathrm{wt} \% \mathrm{FEC}^{26}$ The specific capacity was over $2000 \mathrm{mAh} / \mathrm{g}$ with capacity retention up to $92 \%$ after 100 cycles when the cell was fabricated with mesoporous silicon anode. The internal stress induced by volume expansion of silicon was partially alleviated by the presence of GPE and mesoporous structure of silicon. Although intense efforts had been made in 
the development of polymer electrolytes for LIBs with $\mathrm{Si}$ anode, the overall performance still needs to be improved towards practical application in full cells.

\section{Fluoroethylene carbonate (FEC) additive}

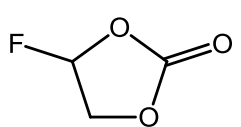

FEC

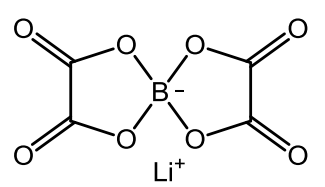

LiBOB

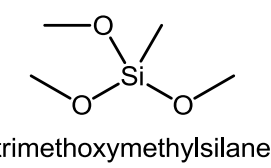

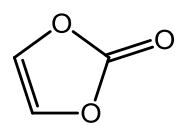

VC<smiles>C1COCO1</smiles>

DOL

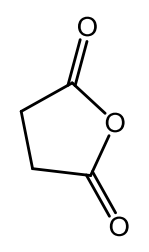

SA

Figure 5. Chemical structures of studied electrolyte additives for Si anode.

Fluoroethylene carbonate (FEC) (structure shown in Figure 5) has been found to be the most effective electrolyte additive for silicon anode. A few percentage of FEC in the conventional carbonate electrolyte significantly improves the electrochemical performance of silicon anode. Studies on FEC additive were initiated by Choi and his colleagues in discovering improved performance with $200-\mathrm{nm}$ Si thin-film anode. ${ }^{27}$ The effectiveness of this additive in promoting half-cell discharge capacity retention and Coulombic efficiency was rationalized by smooth morphology evolution and composition analysis via scanning electron microscopy (SEM) and XPS. In the presence of $3 \mathrm{wt} \%$ FEC in EC:DEC (3:7 in volume) containing 1.3 $\mathrm{M} \mathrm{LiPF}_{6}$, the 
initial Coulombic efficiency and discharge capacity retention were promoted to $88.7 \%$ and $88.5 \%$ at 80 cycles from $87.8 \%$ and $67.9 \%$, respectively.

More recently, performance of FEC (20 wt $\%$ in DMC containing $1 \mathrm{M} \mathrm{LiPF}_{6}$ ) was also demonstrated in LIBs with Si film anode and $\mathrm{LiNi}_{0.5} \mathrm{Mn}_{1.5} \mathrm{O}_{4}$ cathode, and compared to that of EC:DMC (1:1 in mass containing $\left.1 \mathrm{M} \mathrm{LiPF}_{6}\right){ }^{28}$ The amorphous Si anodes with thickness of $\sim 6$ $\mu \mathrm{m}$ were deposited onto current collector via dc magnetron sputtering. While EC and FEC could both contribute to columnar morphology on the thick film, FEC outstood by preventing isolated columns from propagation and subsequent exfoliation. Capacity retention was up to $92.2 \%$ after 200 cycles, $88.5 \%$ after 300 cycles and $74.2 \%$ after 500 cycles, as shown in Figure 6(a). This improvement was also confirmed by X-ray diffraction (XRD) analysis (Figure 6(b) $)^{29}$ and XPS (Figure 6(c) $)^{30}$. The exact chemical composition of the SEI is not fully understood, however, the improved performance was always associated with the presence of decomposition product of $\mathrm{LiF}$. The effectiveness of FEC at improving the Coulombic efficiency and capacity retention is due to fluoride ion formation from reduction of the electrolyte, which leads to the chemical attack of any silicon-oxide surface passivation layers and the formation of a kinetically stable SEI comprising predominately lithium fluoride and lithium oxide. Therefore, an electrochemical reaction of FEC was proposed following a one-electron lithium-assisted reductive decomposition mechanism as show in Figure 7..$^{30}$ 

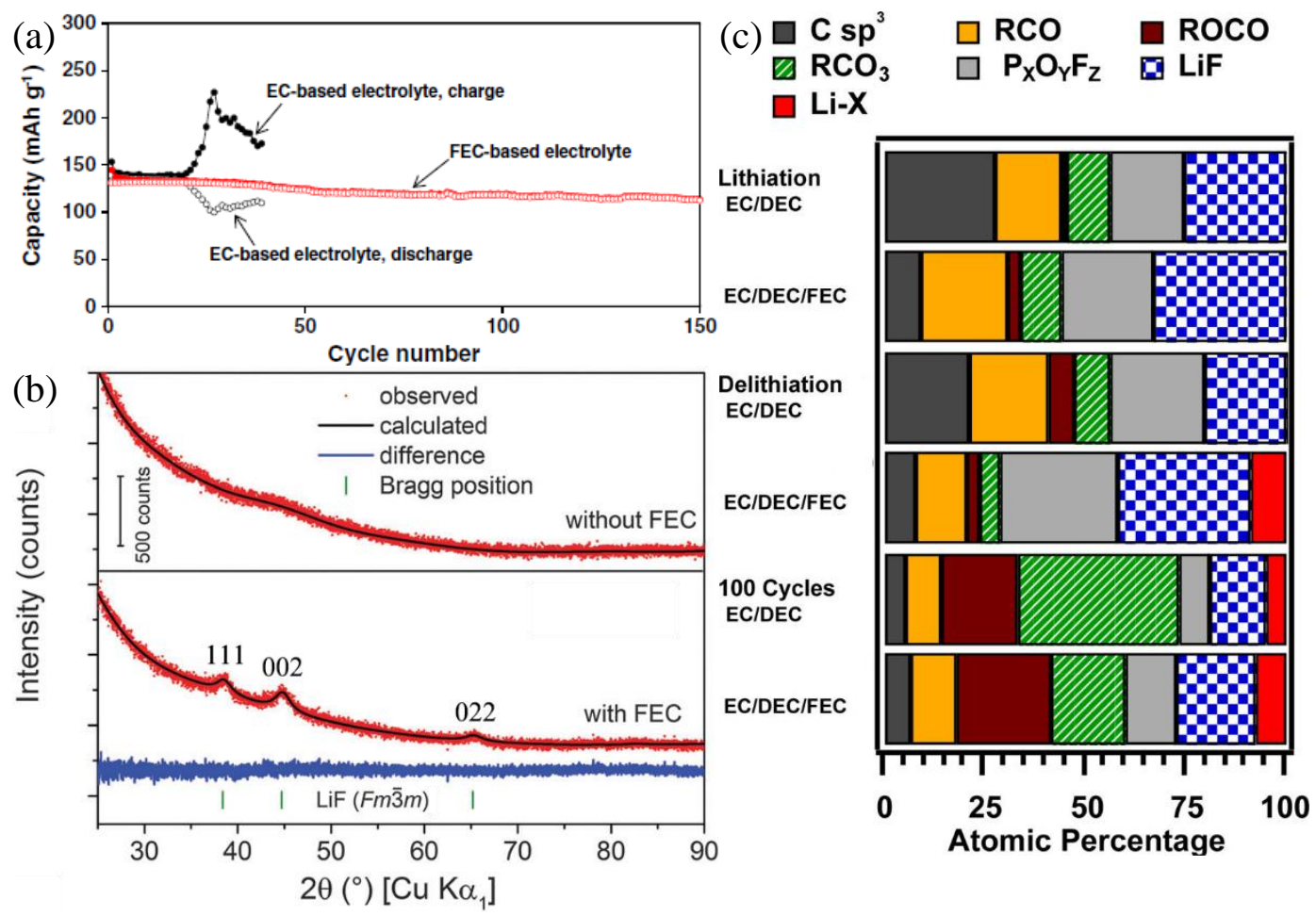

Figure 6. (a) Typical curves of charge (full dots) and discharge (hollow dots) capacity vs. cycle number obtained upon galvanostatic cycling of $\mathrm{Si} \mid \mathrm{LiNi}_{0.5} \mathrm{Mn}_{1.5} \mathrm{O}_{4}$ cells at a current rate of $\mathrm{C} / 8$, referred to the cathode, ${ }^{28}$ (b) XRD profiles of the cycled Si anodes with CMC/SBR depending on FEC addition; ${ }^{29}$ (c) comparison of relative compositions of SEI on thin-film Si anode during $1^{\text {st }}$ cycles of charge and discharge and after 100 cycles in half-cells. ${ }^{30}$ (Reproduced with permission from Elsevier, PCCP Owner Societies and American Chemical Society for a, b and c, respectively) 

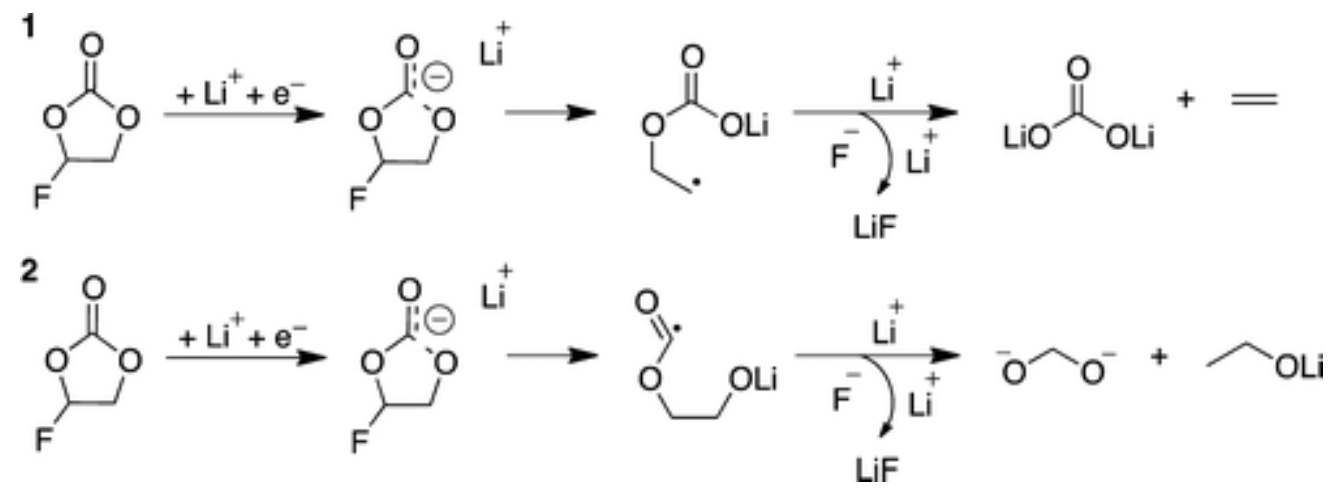

Figure 7. Reaction 1: electroreduction of fluoroethylene carbonate to form lithium fluoride, lithium carbonate, and ethylene; Reaction 2: electroreduction of fluoroethylene carbonate to form lithium fluoride, methylenedioxyl ion (or alternately carbon dioxide), and lithium ethoxide. ${ }^{30}$ (Reproduced with permission from American Chemical Society)

Cell performance improvement was also observed for a LIBs with a pre-lithiated Si film anode (thickness: $\sim 3 \mu \mathrm{m}$ ) coupled with $\mathrm{TiS}_{2}$ cathode. ${ }^{31}$ From morphological perspective, typical features of the columnar amorphous structure of the cycled Si electrodes in FEC based solutions can be observed after $>1000$ cycles, and are similar to the morphology of the pristine electrode while thicker layers were always present on the Si electrodes surface when EC-based electrolyte was used (Figure 8). 

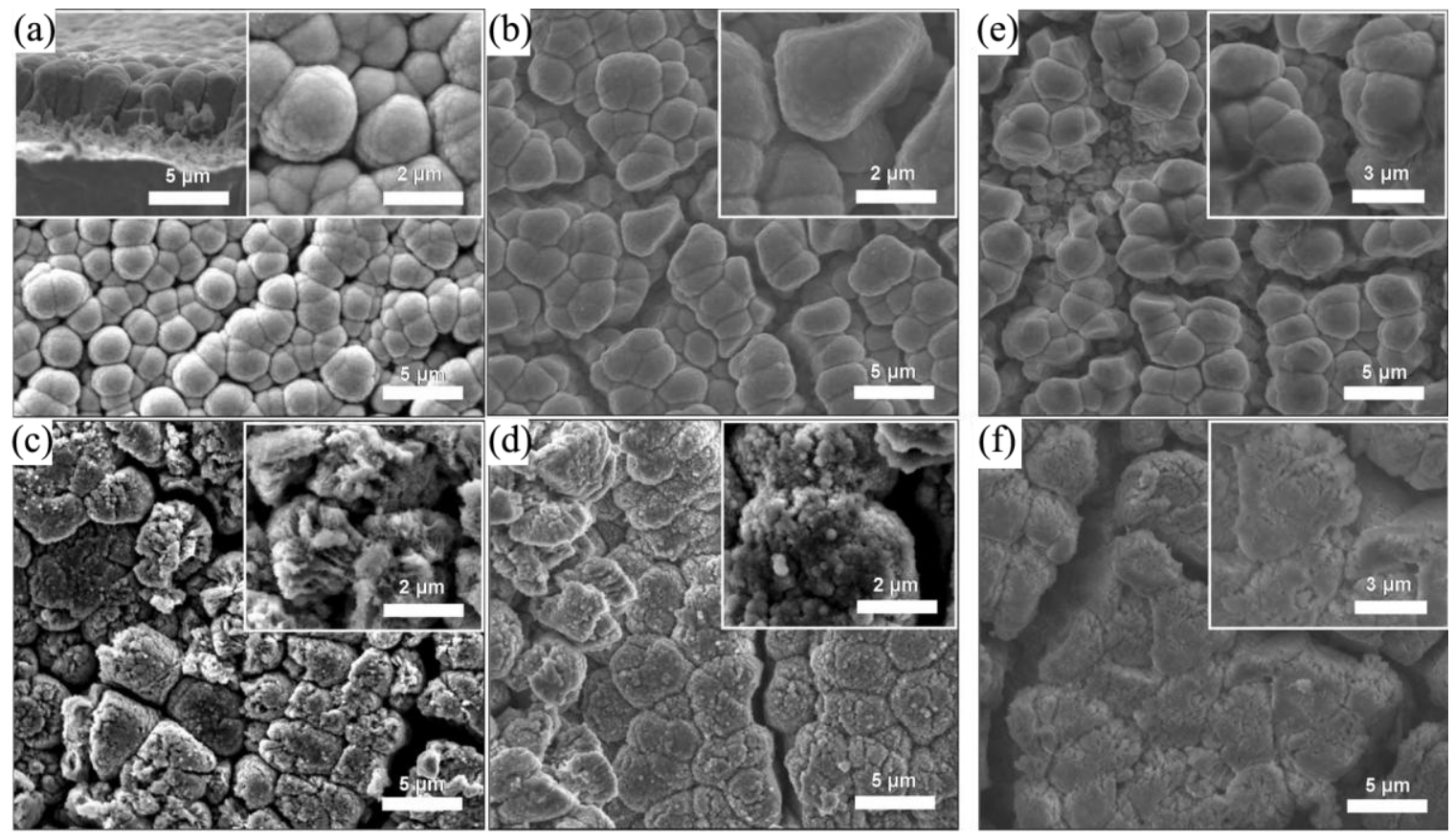

Figure 8. Morphology of pristine amorphous Si electrode (a) with cross section view (left inset), and amorphous Si anodes after the (b) $1^{\text {st }}$, (c) $575^{\text {th }}$, and (d) $1227^{\text {th }}$ cycles after being cycled in FEC-containing electrolyte, and after the (e) $1^{\text {st }}$ and the (f) $180^{\text {th }}$ cycles, in a standard FEC-free electrolyte. $^{31}$ (Reproduced with permission from Electrochemical Society)

LIBs with Si nanowires ${ }^{32}$ and Si nanoparticles ${ }^{29,33}$ fabricated via more advanced techniques were recently analyzed in the presence of FEC and achieved promising results. These results have been further rationalized by varied experimental methods ${ }^{34-35}$ and simulation efforts ${ }^{36-37}$. Numerous studies compared the performance of varied additives to that of FEC and used FEC as a model compound for baseline calibration. ${ }^{33,38-40}$

3,4-Difluoroethylene carbonate (DFEC), a derivative compound of FEC, was also evaluated as an electrolyte additive on thin-film Si anode. ${ }^{41}$ Although inferior to FEC, DFEC still managed to deliver a limiting capacity of $600 \mathrm{mAh} / \mathrm{g}$ for over 1400 cycles at $1 \mathrm{C}$ rate. 


\section{Silane additives}

The surface of silicon consists of silicon oxide $(-\mathrm{Si}-\mathrm{O}-\mathrm{Si}-)$ and silanol $(-\mathrm{Si}-\mathrm{OH})$ which can reductively react with lithium ion, giving rise to irreversible capacity loss. Surface modification by a group of alkoxy silane additives (Figure 5) has been studied. Effects of trimethoxy methyl silane additive on SEI formation on nanocrystalline Si thin-film electrode in $1 \mathrm{M} \mathrm{LiPF}_{6} /$ ethylene carbonate:diethyl carbonate1:1 electrolyte were studied using ATR-FTIR. It was found that silane effectively protected the Si surface by formation of a stable SEI layer composed of organics with alkyl carbonate and carboxylic acid metal salt functionalities, and PF-containing species, leading to a stable cycling at $0.1-1.5 \mathrm{~V}$ vs $\mathrm{Li} / \mathrm{Li}^{+}$delivering $2400 \mathrm{mAh} / \mathrm{g}$ over 200 cycles. The film surface obtained after cycling without silane, however, showed primarily PF-containing species, which is responsible for inefficient passivation of the $\mathrm{Si}$ surface, resulting in a rapid capacity fade. Silane additives with multi-alkoxy substitutions were also studied to analyze the effect of substituents. ${ }^{42}$ Alkoxysilane functionalities were confirmed to be effective in construction of stable SEI in LIBs with Si anode.

\section{Other additives}

Vinylene carbonate (VC) was inspired by prior reports in LIBs with graphite anode and identified as an effective additive for LIBs with Si thin-film anode. ${ }^{43-44}$ In the presence of $1 \mathrm{wt} \%$ VC in EC:DMC (1:1 in volume) containing $1 \mathrm{M} \mathrm{LiPF}_{6}$, the initial Coulombic efficiency was promoted to $72.5 \%$ from $67.9 \%$. The reversible capacity in VC-containing electrolyte was stable at $\sim 2000 \mathrm{mAh} / \mathrm{g}$ even up to 200 cycles, and gradually decayed to more than $500 \mathrm{mAh} / \mathrm{g}$ after 500 cycles. The morphology of SEI layer from VC-containing electrolyte was smooth and 
uniform as observed via SEM, and the impedance remained invariant with respect to cycle number as evidenced by EIS. The elemental and chemical compositions of SEI layer from VCcontaining electrolyte were qualitatively determined by EDX and FTIR, and further quantified by XPS. Oxidation of $\mathrm{Si}$ was considered primarily in $\mathrm{Li}^{+}$insertion process with EC when SEI layer was broken in the valleys as captured by SEM. Artificial SEI can also be constructed via atomic layer deposition (ALD) of reduced graphene oxide (rGO) and carbon nanotube (CNT) onto Si nanoparticles, and contributed to further improvement in addition to $\mathrm{VC}^{45}$

Exceptional electrochemical performance of 1,3-dioxolane (DOL) was recognized on LIBs with Si nanowire anode, and could be used with solely LiTFSI or in conjunction with $\mathrm{LiNO}_{3}{ }^{46}$ Formation of flexible and elastic SEI layers was considered as the polymerization product of DOL, accommodating the volume change of anode during cycling. The discharge capacity with

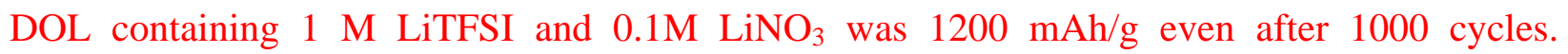
Comparative studies confirmed that $\mathrm{DOL} / \mathrm{LiNO}_{3}$ delivered the best cycling performance in LIBs with porous $\mathrm{Si} / \mathrm{C}$ nanocomposite anode. ${ }^{47}$

Succinic anhydride (SA) was discovered by recognition of its superior electrochemical performance over amorphous Si film anode. ${ }^{48}$ The discharge capacity was $\sim 1800 \mathrm{mAh} / \mathrm{g}$ after 100 cycles, which was attributed to suppressed decomposition of $\mathrm{LiPF}_{6}$ on Si surface.

Later studies of SA on LIBs with $\mathrm{Si} / \mathrm{C}$ nanowire anode fabricated via electrospin confirmed its effectiveness in EC:DEC:DMC (1:1:1 in volume) containing $1 \mathrm{M} \mathrm{LiPF}_{6}{ }^{49}$ In addition, by careful control over state-of-charge condition at $70 \%$ in the presence of a polymer binder, capacity fading rate could be reduced significantly, and discharge capacity could be maintained over 600 $\mathrm{mAh} / \mathrm{g}$ after 150 cycles. 
Similar to FEC, research of lithium bis(oxalato)borate (LiBOB) in LIBs with $\mathrm{Si}$ anode was initiated by transplanting from its application in LIBs with graphite anode ${ }^{50}$ Performance of ED/DEC (3:7 in volume) containing 0.7 M LiBOB was evaluated in LIBs with Si thin-film anode, and compared to that containing 1.3 $\mathrm{M} \mathrm{LiPF}_{6}$. LiBOB was confirmed to be effective in reducing lithium consumption by trapping lithium in the Si anode and constructing an SEI layer. It was proposed that the reductive decomposition of $\mathrm{LiBOB}$ proceeded relatively fast with respect to $\mathrm{LiPF}_{6}$ and thus suppressed the electrochemical reactions of lithiated $\mathrm{Si}$ with electrolyte and the consequent formation of cracks on $\mathrm{Si}$ anode. Isolated (inactive) $\mathrm{Si}$ particles could therefore be limited by maintaining the integrity of thin-film anode. The initial Coulombic efficiency and discharge capacity retention in the presence of $0.7 \mathrm{M} \mathrm{LiBOB}$ were promoted to $88.1 \%$ and $83.5 \%$ at 100 cycles, compared to $87.8 \%$ and $50.8 \%$, respectively for $1.3 \mathrm{M} \mathrm{LiPF}_{6}$ electrolyte.

Lithium difluoro(oxalato)borate (LiDFOB) was also examined, and delivered slightly better performance in half-cell LIBs with Si film anode compared to its analog LiBOB. ${ }^{38}$

Tris(pentafluorophenyl) borane (TPFPB) (Figure 5) was later demonstrated as an effective additive for LIBs with Si thin-film anode (thickness: 40 nm). ${ }^{51}$ The performance of LIBs in the presence of TPFPB was very much dependent on additive concentration, and comparable to FEC and SA but slightly superior to VC. In the presence of $5 \mathrm{wt} \%$ TPFPB in EC:DEC (1:1 in volume) containing $1 \mathrm{M} \mathrm{LiClO}_{4}$, the discharge capacity was $1808.6 \mathrm{mAh} / \mathrm{g}$ with capacity retention of $87.2 \%$ after 100 cycles. Perfluoroglutaric acid diemthyl ester $\left(\mathrm{PF}_{5} \mathrm{M}_{2}\right)$ was evaluated against LIBs with $\mathrm{Si}$ film anode, although the conductivity was low compared to conventional electrolytes. $^{52}$

\section{Future direction}


In the present review article, the most recent advances in the electrolyte and electrolyte additive for LIBs with Si anode were reviewed systematically. Despite the advantages of the silicon materials, a number of challenges impede its commercialization. While the commercialized graphite electrode expands $10-13 \%$ during lithium intercalation, silicon expansion amounts to nearly $300 \%$, generating structural degradation and instability of the all-important SEI. Such instabilities ultimately shorten the battery life to inadequate levels. Degradation of the active material can be mitigated by incorporating materials with dimensions of less than $150 \mathrm{~nm}$; however, research has not yet developed a practical solution to expansion-induced breaking of conductive channels, active material isolation and continuous SEI reformation. Building a robust SEI on the silicon anode electrochemically or through a surface modification is pivotal for the improved performance of $\mathrm{Si}$ anode. Ultimately, a combinatorial approach involving a mechanically resilient electrode architecture coupled with an electrolyte/additive capable of forming a stable SEI, is the most promising strategy to integrate structural integrity with stable interfacial chemistry.

Furthermore, the current understanding of the lithium reaction mechanisms on the surface of $\mathrm{Si}$ anodes employs assumptions about mechanisms and material properties that are not fully validated. Therefore, it is critically important to quantitatively explore the lithiation and delithiation processes in operando mode (in-situ SEM, transmission electron microscopy (TEM) and XRD) to provide invaluable information for designing functional electrolyte and additives for $\mathrm{Si}$ anode. A reverse-engineered approach to fabricate stable SEI via ex-situ formation (polymerization, encapsulation, etc.) and rational design of binder materials are envisioned to deliver better performance of LIBs with Si anode. 
Table 1. Cell Performance of LIBs with Si anode with ionic liquid electrolytes

\begin{tabular}{|c|c|c|c|c|c|c|c|c|c|c|c|}
\hline Cell architecture & $\begin{array}{l}\text { Anode } \\
\text { fabrication }\end{array}$ & Anode Form & Binder & Electrolyte & $\begin{array}{l}\text { Initial } \\
\text { Capacity, } \\
\mathrm{mAh} / \mathrm{g}\end{array}$ & $\begin{array}{l}\text { Initial } \\
\text { Coulombic } \\
\text { Efficiency }\end{array}$ & $\begin{array}{l}\text { Coulombic } \\
\text { Efficiency, } \\
(\text { Cycle \#) }\end{array}$ & $\begin{array}{l}\text { Capacity }(\mathrm{mAh} / \mathrm{g}) \\
\text { or Capacity } \\
\text { Retention } \\
(\text { Cycle \#) }\end{array}$ & $\begin{array}{l}\text { Cutoff } \\
\text { voltage } \\
\text { (V) }\end{array}$ & $\begin{array}{l}\text { Rate } \\
\text { (C) }\end{array}$ & Ref. \\
\hline $\mathrm{Si} \mid \mathrm{Li}$ & $\begin{array}{l}\text { DC magnetron } \\
\text { sputtering }\end{array}$ & $\begin{array}{l}\text { Thin film, } \\
100 \mathrm{~nm}\end{array}$ & & $\begin{array}{l}1 \mathrm{M} \text { LiTFSI in } \\
\mathrm{PP}_{13} \text { TFSI }\end{array}$ & & & & $3000(38)$ & & 0.0625 & 20 \\
\hline $\mathrm{Si} \mid \mathrm{LiCoO}_{2}$ & $\begin{array}{l}\text { DC magnetron } \\
\text { sputtering }\end{array}$ & $\begin{array}{l}\text { Thin film, } \\
100 \mathrm{~nm}\end{array}$ & & $\begin{array}{l}1 \mathrm{M} \text { LiTFSI in } \\
\mathrm{PP}_{13} \text { TFSI }\end{array}$ & & & & $1000(32)$ & $3-4.3$ & 0.1 & 20 \\
\hline$(\mathrm{Si} / \mathrm{Cu}) \mid \mathrm{Li}$ & $\begin{array}{l}\text { Pulsed laser } \\
\text { deposition }\end{array}$ & $\begin{array}{l}\text { Thin film, } \\
60 \mathrm{~nm}\end{array}$ & & $\begin{array}{l}1 \mathrm{M} \text { LiTFSI in } \\
\text { PYR }_{13} \text { TFSI }\end{array}$ & & & & $1500(200)$ & $0.1-1.5$ & & 18 \\
\hline$(\mathrm{Si} / \mathrm{Ni} / \mathrm{C}) \mid \mathrm{Li}$ & $\begin{array}{l}\text { Mechanical } \\
\text { milling }\end{array}$ & Fine powder & PVDF & $\begin{array}{lr}0.3 & \mathrm{~mol} / \mathrm{kg} \\
\text { LiTFSI } & \text { in } \\
\text { EMIFSI } & \end{array}$ & & & $100(20)$ & $900(20)$ & $\begin{array}{l}0.005- \\
1.5\end{array}$ & & 23 \\
\hline $\mathrm{Si} \mid \mathrm{Li}$ & $\begin{array}{l}\text { Chemical } \\
\text { vapor } \\
\text { deposition }\end{array}$ & $\begin{array}{l}\text { Fiber, } \\
80-100 \mathrm{~nm}\end{array}$ & & $\begin{array}{l}1 \mathrm{M} \text { LiTFSI in } \\
\text { BTMATFSI } \\
\text { with } 10 \mathrm{wt} \% \mathrm{PC}\end{array}$ & 1800 & 91 & $93(50)$ & $1000(50)$ & $\begin{array}{l}0.001- \\
2.0\end{array}$ & 0.05 & 24 \\
\hline$(\mathrm{Si} / \mathrm{Cu}) \mid \mathrm{Li}$ & $\begin{array}{l}\text { Pulsed laser } \\
\text { deposition }\end{array}$ & $\begin{array}{l}\text { Thin film, } \\
60 \mathrm{~nm}\end{array}$ & & $\begin{array}{l}1 \mathrm{M} \text { LiTFSI in } \\
\text { PYR }_{13} \text { TFSI }\end{array}$ & 1650 & 69 & & & $0.1-1.5$ & & 53 \\
\hline$\left(\mathrm{LaSi}_{2} / \mathrm{Si}\right) \mid \mathrm{Li}$ & Gas deposition & $\begin{array}{l}\text { Thin film, } \\
2-4 \mu \mathrm{m}\end{array}$ & & $\begin{array}{l}1 \mathrm{M} \text { LiTFSI in } \\
\mathrm{PP}_{13} \mathrm{FSI}\end{array}$ & 3200 & & & $2900(250)$ & $\begin{array}{l}0.005- \\
2.0\end{array}$ & 0.25 & 21 \\
\hline$\left(\mathrm{LaSi}_{2} / \mathrm{Si}\right) \mid \mathrm{Li}$ & Gas deposition & $\begin{array}{l}\text { Thin film, } \\
2-4 \mu \mathrm{m}\end{array}$ & & $\begin{array}{l}1 \mathrm{M} \text { LiTFSI in } \\
\mathrm{PP}_{13} \text { TFSI }\end{array}$ & 1500 & & & $1500(250)$ & $\begin{array}{l}0.005- \\
2.0\end{array}$ & 0.25 & 21 \\
\hline $\mathrm{Si} \mid \mathrm{Li}$ & Gas deposition & $\begin{array}{l}\text { Thin film, } \\
2 \mu \mathrm{m}\end{array}$ & & $\begin{array}{l}1 \mathrm{M} \text { LiTFSI in } \\
\mathrm{PP}_{1 \mathrm{MEM}} \text { TFSI }\end{array}$ & 2670 & 85 & $100(100)$ & $1000(100)$ & $\begin{array}{l}0.005- \\
2.0\end{array}$ & 0.12 & 22 \\
\hline $\mathrm{Si} \mid \mathrm{Li}$ & Gas deposition & $\begin{array}{l}\text { Thin film, } \\
2 \mu \mathrm{m}\end{array}$ & & $\begin{array}{l}1 \mathrm{M} \text { LiTFSI in } \\
\mathrm{PP}_{16} \text { TFSI }\end{array}$ & 1770 & 70 & 99 (100) & $1000(100)$ & $\begin{array}{l}0.005- \\
2.0\end{array}$ & 0.12 & 22 \\
\hline
\end{tabular}




\begin{tabular}{|c|c|c|c|c|c|c|c|c|c|c|c|}
\hline $\mathrm{cSi} \mid \mathrm{Li}^{a}$ & $\begin{array}{l}\text { Mechanical } \\
\text { milling }\end{array}$ & $\begin{array}{l}\text { Particles, } \\
50 \mathrm{~nm}\end{array}$ & $\begin{array}{l}\text { cPAN } \\
b\end{array}$ & $\begin{array}{l}1.2 \mathrm{M} \text { LiFSI in } \\
\text { PYR }_{13} \mathrm{FSI}\end{array}$ & $>2000$ & & $100(200)$ & $76.7 \%(100)$ & $0.05-1.0$ & 0.1 & 19 \\
\hline $\mathrm{cSi} \mid \mathrm{Li}$ & $\begin{array}{l}\text { Mechanical } \\
\text { milling }\end{array}$ & $\begin{array}{l}\text { Particles, } \\
50 \mathrm{~nm}\end{array}$ & cPAN & $\begin{array}{l}0.6 \mathrm{M} \text { LiTFSI in } \\
\text { PYR }_{13} \text { TFSI }\end{array}$ & 1000 & 80 & $75(100)$ & & $0.05-1.0$ & 0.1 & 19 \\
\hline $\mathrm{cSi} \mid \mathrm{Li}$ & $\begin{array}{l}\text { Mechanical } \\
\text { milling }\end{array}$ & $\begin{array}{l}\text { Particles, } \\
50 \mathrm{~nm}\end{array}$ & cPAN & $\begin{array}{l}1.2 \mathrm{M} \text { LiFSI in } \\
\text { EMIFSI }\end{array}$ & 2500 & 94 & $100(100)$ & $2000(100)$ & $0.05-1.0$ & 0.1 & 19 \\
\hline cSi|NMC111 & $\begin{array}{l}\text { Mechanical } \\
\text { milling }\end{array}$ & $\begin{array}{l}\text { Particles, } \\
50 \mathrm{~nm}\end{array}$ & cPAN & $\begin{array}{l}1.2 \mathrm{M} \mathrm{LiFSI} \text { in } \\
\text { PYR }_{13} \mathrm{FSI}\end{array}$ & 2000 & 100 & $100(1000)$ & $50 \%(1000)$ & $2-4.15$ & 0.5 & 19 \\
\hline
\end{tabular}

a. cSi, crystalline silicon.

b. cPAN, cyclized polyacrylonitrile. 


\section{Acknowledgements}

This research is supported by the U.S. Department of Energy, Vehicle Technologies Office. Argonne National Laboratory is operated for the U.S. Department of Energy by UChicago Argonne, LLC, under contract DE-AC02-06CH11357.

Reference

1. Armand, M.; Endres, F.; MacFarlane, D. R.; Ohno, H.; Scrosati, B., Ionic-liquid materials for the electrochemical challenges of the future. Nat Mater 2009, 8 (8), 621-629.

2. Tarascon, J. M.; Armand, M., Issues and challenges facing rechargeable lithium batteries. Nature 2001, 414 (6861), 359-367.

3. Armand, M.; Tarascon, J. M., Building better batteries. Nature 2008, 451 (7179), 652-657.

4. $\quad \mathrm{Xu}, \mathrm{B}$.; Qian, D.; Wang, Z.; Meng, Y. S., Recent progress in cathode materials research for advanced lithium ion batteries. Materials Science and Engineering: R: Reports 2012, 73 (5-6), 51-65.

5. Ji, L.; Lin, Z.; Alcoutlabi, M.; Zhang, X., Recent developments in nanostructured anode materials for rechargeable lithium-ion batteries. Energy \& Environmental Science 2011, 4 (8), 2682-2699.

6. Thackeray, M. M.; Wolverton, C.; Isaacs, E. D., Electrical energy storage for transportationapproaching the limits of, and going beyond, lithium-ion batteries. Energy \& Environmental Science 2012, 5 (7), 7854-7863.

7. Wu, H.; Cui, Y., Designing nanostructured Si anodes for high energy lithium ion batteries. Nano Today 2012, 7 (5), 414-429.

8. Zhang, W.-J., A review of the electrochemical performance of alloy anodes for lithium-ion batteries. Journal of Power Sources 2011, 196 (1), 13-24.

9. Park, C.-M.; Kim, J.-H.; Kim, H.; Sohn, H.-J., Li-alloy based anode materials for Li secondary batteries. Chemical Society Reviews 2010, 39 (8), 3115-3141.

10. Reddy, M. V.; Subba Rao, G. V.; Chowdari, B. V. R., Metal Oxides and Oxysalts as Anode Materials for Li Ion Batteries. Chemical Reviews 2013, 113 (7), 5364-5457.

11. Obrovac, M. N.; Christensen, L., Structural Changes in Silicon Anodes during Lithium Insertion/Extraction. Electrochemical and Solid-State Letters 2004, 7 (5), A93-A96.

12. Morachevskii, A. G.; Demidov, A. I., Lithium-silicon alloys: Phase diagram, electrochemical studies, thermodynamic properties, application in chemical power cells. Russian Journal of Applied Chemistry 2015, 88 (4), 547-566. 
*A recent review restating the significance of phase behavior and electrochemical properties of lithiumsilicon binary alloy, particularly for applications in LIBs. The calculation laid the foundation of understanding electrochemical processes during lithiation and delithiation in LIBs with silicon anode. 13. Yen, Y.-C.; Chao, S.-C.; Wu, H.-C.; Wu, N.-L., Study on Solid-Electrolyte-Interphase of Si and C-Coated Si Electrodes in Lithium Cells. Journal of The Electrochemical Society 2009, 156 (2), A95A102.

14. Michan, A. L.; Leskes, M.; Grey, C. P., Voltage Dependent Solid Electrolyte Interphase Formation in Silicon Electrodes: Monitoring the Formation of Organic Decomposition Products. Chemistry of Materials 2016, 28 (1), 385-398.

**A comprehensive study on decomposition products of EC/DMC in LIBs with silicon anode performed by ssNMR. For the first time, SEI compositions of LIBs with silicon anode were quantified by means of NMR technqiues.

15. Hassoun, J.; Scrosati, B., Review-Advances in Anode and Electrolyte Materials for the Progress of Lithium-Ion and beyond Lithium-Ion Batteries. Journal of The Electrochemical Society 2015, 162 (14), A2582-A2588.

**A recent review on progressive development of anode and electrolyte materials in LIBs. Varied alloys, graphene and transition metal oxides were reviewed on anode development. Polymer, gel, solid state and IL electrolytes were emphasized.

16. Gebresilassie Eshetu, G.; Armand, M.; Scrosati, B.; Passerini, S., Energy Storage Materials Synthesized from Ionic Liquids. Angewandte Chemie International Edition 2014, 53 (49), 13342-13359. 17. Howlett, P. C.; MacFarlane, D. R.; Hollenkamp, A. F., High Lithium Metal Cycling Efficiency in a Room-Temperature Ionic Liquid. Electrochemical and Solid-State Letters 2004, 7 (5), A97-A101. 18. Nguyen, C. C.; Song, S.-W., Characterization of SEI layer formed on high performance $\mathrm{Si}-\mathrm{Cu}$ anode in ionic liquid battery electrolyte. Electrochemistry Communications 2010, 12 (11), 1593-1595. 19. Piper, D. M.; Evans, T.; Leung, K.; Watkins, T.; Olson, J.; Kim, S. C.; Han, S. S.; Bhat, V.; Oh, K. H.; Buttry, D. A.; Lee, S.-H., Stable silicon-ionic liquid interface for next-generation lithium-ion batteries. Nat Commun 2015, 6 .

**A pioneering work on ILs in LIBs with silicon anode. Nano-sized silicon partilces were engineered by polymer coating to accommodate volume expansion of anode. Advanced characterization techiques were applied to offer deep understanding on the decomposition mechanism of ILs.

20. Baranchugov, V.; Markevich, E.; Pollak, E.; Salitra, G.; Aurbach, D., Amorphous silicon thin films as a high capacity anodes for Li-ion batteries in ionic liquid electrolytes. Electrochemistry

Communications 2007, 9 (4), 796-800. 
21. Usui, H.; Shimizu, M.; Sakaguchi, H., Applicability of ionic liquid electrolytes to LaSi2/Si composite thick-film anodes in Li-ion battery. Journal of Power Sources 2013, 235, 29-35.

22. Shimizu, M.; Usui, H.; Matsumoto, K.; Nokami, T.; Itoh, T.; Sakaguchi, H., Effect of Cation Structure of Ionic Liquids on Anode Properties of Si Electrodes for LIB. Journal of The Electrochemical Society 2014, 161 (12), A1765-A1771.

23. Sugimoto, T.; Atsumi, Y.; Kono, M.; Kikuta, M.; Ishiko, E.; Yamagata, M.; Ishikawa, M., Application of bis(fluorosulfonyl)imide-based ionic liquid electrolyte to silicon-nickel-carbon composite anode for lithium-ion batteries. Journal of Power Sources 2010, 195 (18), 6153-6156.

24. Chakrapani, V.; Rusli, F.; Filler, M. A.; Kohl, P. A., Quaternary Ammonium Ionic Liquid Electrolyte for a Silicon Nanowire-Based Lithium Ion Battery. The Journal of Physical Chemistry C 2011, 115 (44), 22048-22053.

25. Haruta, M.; Masuo, Y.; Moriyasu, T.; Tomita, A.; Sakakibara, C.; Kamei, A.; Hirota, M.; Takenaka, T.; Doi, T.; Inaba, M., Cycle Performances of Si-flake-powder Anodes in Lithium Salttetraglyme Complex Electrolytes. Electrochemistry 2015, 83 (10), 837-839.

*An initiative work on oligomeric PEO electrolyte in LIBs with Si-flake powder. Tetraglyme/LiTFSI complex electrolyte was explored in the presence of FEC and 1,1,2,2-tetrafluoroethyl-2,2,3,3tetrafluoropropyl ether (HFE).

26. Bok, T.; Cho, S.-J.; Choi, S.; Choi, K.-H.; Park, H.; Lee, S.-Y.; Park, S., An effective coupling of nanostructured $\mathrm{Si}$ and gel polymer electrolytes for high-performance lithium-ion battery anodes. RSC Advances 2016, 6 (9), 6960-6966.

**An innovative work on GPE for LIBs with silicon anode. Both nanostructured and microporous silicon particles were considered for comparison purposes.

27. Choi, N.-S.; Yew, K. H.; Lee, K. Y.; Sung, M.; Kim, H.; Kim, S.-S., Effect of fluoroethylene carbonate additive on interfacial properties of silicon thin-film electrode. Journal of Power Sources 2006, 161 (2), 1254-1259.

28. Fridman, K.; Sharabi, R.; Elazari, R.; Gershinsky, G.; Markevich, E.; Salitra, G.; Aurbach, D.; Garsuch, A.; Lampert, J., A new advanced lithium ion battery: Combination of high performance amorphous columnar silicon thin film anode, $5 \mathrm{~V}$ LiNi0.5Mn1.5O4 spinel cathode and fluoroethylene carbonate-based electrolyte solution. Electrochemistry Communications 2013, 33, 31-34.

29. Jaumann, T.; Balach, J.; Klose, M.; Oswald, S.; Langklotz, U.; Michaelis, A.; Eckert, J.; Giebeler, L., SEI-component formation on sub $5 \mathrm{~nm}$ sized silicon nanoparticles in Li-ion batteries: the role of electrode preparation, FEC addition and binders. Physical Chemistry Chemical Physics 2015, 17 (38), 24956-24967. 
**A systematic study on the formation mechanism of SEI via decompositoin of electrolyte and FEC. Morphology and composition of electrode fabricated with were analyzed via electron microscopy, XRD and XPS.

30. Schroder, K.; Alvarado, J.; Yersak, T. A.; Li, J.; Dudney, N.; Webb, L. J.; Meng, Y. S.; Stevenson, K. J., The Effect of Fluoroethylene Carbonate as an Additive on the Solid Electrolyte Interphase on Silicon Lithium-Ion Electrodes. Chemistry of Materials 2015, 27 (16), 5531-5542. **A comprehensive mechanistic study on decomposition of FEC. A detailed comparison was made on decomposition prodcut of electrolyte with and without addition of FEC via XPS and impedance measurement.

31. Elazari, R.; Salitra, G.; Gershinsky, G.; Garsuch, A.; Panchenko, A.; Aurbach, D., Li Ion Cells Comprising Lithiated Columnar Silicon Film Anodes, TiS2 Cathodes and Fluoroethyene Carbonate (FEC) as a Critically Important Component. Journal of The Electrochemical Society 2012, 159 (9), A1440A1445.

32. Etacheri, V.; Haik, O.; Goffer, Y.; Roberts, G. A.; Stefan, I. C.; Fasching, R.; Aurbach, D., Effect of Fluoroethylene Carbonate (FEC) on the Performance and Surface Chemistry of Si-Nanowire Li-Ion Battery Anodes. Langmuir 2012, 28 (1), 965-976.

33. Profatilova, I. A.; Stock, C.; Schmitz, A.; Passerini, S.; Winter, M., Enhanced thermal stability of a lithiated nano-silicon electrode by fluoroethylene carbonate and vinylene carbonate. Journal of Power Sources 2013, 222, 140-149.

34. Shkrob, I. A.; Wishart, J. F.; Abraham, D. P., What Makes Fluoroethylene Carbonate Different? The Journal of Physical Chemistry C 2015, 119 (27), 14954-14964.

**A distinguished perspctive on decomposition mechanism of FEC in LIBs with silicon anode. Reduction chemistry of FEC was established via radiolysis, laser photoionization, electron paramagnetic resonance, and transient absorption spectroscopy.

35. Xu, C.; Lindgren, F.; Philippe, B.; Gorgoi, M.; Björefors, F.; Edström, K.; Gustafsson, T., Improved Performance of the Silicon Anode for Li-Ion Batteries: Understanding the Surface Modification Mechanism of Fluoroethylene Carbonate as an Effective Electrolyte Additive. Chemistry of Materials 2015, 27 (7), 2591-2599.

**A comprehensive investigation on decomposition mechanism of electrolyte and FEC in LIBs with silicon anode via XPS and electron microscopy.

36. Chen, X.; Li, X.; Mei, D.; Feng, J.; Hu, M. Y.; Hu, J.; Engelhard, M.; Zheng, J.; Xu, W.; Xiao, J.; Liu, J.; Zhang, J.-G., Reduction Mechanism of Fluoroethylene Carbonate for Stable Solid-Electrolyte Interphase Film on Silicon Anode. ChemSusChem 2014, 7 (2), 549-554. 
37. Martinez de la Hoz, J. M.; Soto, F. A.; Balbuena, P. B., Effect of the Electrolyte Composition on SEI Reactions at Si Anodes of Li-Ion Batteries. The Journal of Physical Chemistry C 2015, 119 (13), 7060-7068.

*An indepth computational investigation on the compositions of varied electrolyte components.

38. Dalavi, S.; Guduru, P.; Lucht, B. L., Performance Enhancing Electrolyte Additives for Lithium Ion Batteries with Silicon Anodes. Journal of The Electrochemical Society 2012, 159 (5), A642-A646.

39. Nguyen, C. C.; Lucht, B. L., Comparative Study of Fluoroethylene Carbonate and Vinylene Carbonate for Silicon Anodes in Lithium Ion Batteries. Journal of The Electrochemical Society 2014, 161 (12), A1933-A1938.

40. Uchida, S.; Yamagata, M.; Ishikawa, M., Effect of Electrolyte Additives on Non-Nano-Si Negative Electrodes Prepared with Polyimide Binder. Journal of The Electrochemical Society 2015, 162 (3), A406-A412.

41. Markevich, E.; Fridman, K.; Sharabi, R.; Elazari, R.; Salitra, G.; Gottlieb, H. E.; Gershinsky, G.; Garsuch, A.; Semrau, G.; Schmidt, M. A.; Aurbach, D., Amorphous Columnar Silicon Anodes for Advanced High Voltage Lithium Ion Full Cells: Dominant Factors Governing Cycling Performance. Journal of The Electrochemical Society 2013, 160 (10), A1824-A1833.

42. Ryu, Y.-G.; Lee, S.; Mah, S.; Lee, D. J.; Kwon, K.; Hwang, S.; Doo, S., Electrochemical Behaviors of Silicon Electrode in Lithium Salt Solution Containing Alkoxy Silane Additives. Journal of The Electrochemical Society 2008, 155 (8), A583-A589.

43. Chen, L.; Wang, K.; Xie, X.; Xie, J., Effect of vinylene carbonate (VC) as electrolyte additive on electrochemical performance of Si film anode for lithium ion batteries. Journal of Power Sources 2007, 174 (2), 538-543.

44. Chen, L.; Wang, K.; Xie, X.; Xie, J., Enhancing Electrochemical Performance of Silicon Film Anode by Vinylene Carbonate Electrolyte Additive. Electrochemical and Solid-State Letters 2006, 9 (11), A512-A515.

45. Hy, S.; Chen, Y.-H.; Cheng, H.-M.; Pan, C.-J.; Cheng, J.-H.; Rick, J.; Hwang, B.-J., Stabilizing Nanosized Si Anodes with the Synergetic Usage of Atomic Layer Deposition and Electrolyte Additives for Li-Ion Batteries. ACS Applied Materials \& Interfaces 2015, 7 (25), 13801-13807.

*A pioneering work on LIBs with silicon anode fabricated by nanotechnology. Siliocn particles on dimension of nano-scale were decorated by conductive carbon materials, and the electrode was decorated by ALD.

46. Etacheri, V.; Geiger, U.; Gofer, Y.; Roberts, G. A.; Stefan, I. C.; Fasching, R.; Aurbach, D., Exceptional Electrochemical Performance of Si-Nanowires in 1,3-Dioxolane Solutions: A Surface Chemical Investigation. Langmuir 2012, 28 (14), 6175-6184. 
47. Jaumann, T.; Balach, J.; Klose, M.; Oswald, S.; Eckert, J.; Giebeler, L., Role of 1,3-Dioxolane and LiNO3 Addition on the Long Term Stability of Nanostructured Silicon/Carbon Anodes for Rechargeable Lithium Batteries. Journal of The Electrochemical Society 2016, 163 (3), A557-A564. **A good demonstration of application of nanocomposite in LIBs with silicon anode. Effect of $\mathrm{LiNO}_{3}$ and DOL were investigated systematically via electrochemical methods, XRD and XPS.

48. Han, G.-B.; Ryou, M.-H.; Cho, K. Y.; Lee, Y. M.; Park, J.-K., Effect of succinic anhydride as an electrolyte additive on electrochemical characteristics of silicon thin-film electrode. Journal of Power Sources 2010, 195 (11), 3709-3714.

49. Li, Y.; Xu, G. J.; Yao, Y. F.; Xue, L. G.; Zhang, S.; Lu, Y.; Toprakci, O.; Zhang, X. W., Improvement of cyclability of silicon-containing carbon nanofiber anodes for lithium-ion batteries by employing succinic anhydride as an electrolyte additive. J Solid State Electr 2013, 17 (5), 1393-1399.

50. Choi, N.-S.; Yew, K. H.; Kim, H.; Kim, S.-S.; Choi, W.-U., Surface layer formed on silicon thinfilm electrode in lithium bis(oxalato) borate-based electrolyte. Journal of Power Sources 2007, 172 (1), 404-409.

51. Han, G.-B.; Lee, J.-N.; Choi, J. W.; Park, J.-K., Tris(pentafluorophenyl) borane as an electrolyte additive for high performance silicon thin film electrodes in lithium ion batteries. Electrochimica Acta 2011, 56 (24), 8997-9003.

52. Fears, T. M.; Sacci, R. L.; Winiarz, J. G.; Kaiser, H.; Taub, H.; Veith, G. M., A study of perfluorocarboxylate ester solvents for lithium ion battery electrolytes. Journal of Power Sources 2015, 299, 434-442.

53. Nguyen, C. C.; Woo, S.-W.; Song, S.-W., Understanding the Interfacial Processes at SiliconCopper Electrodes in Ionic Liquid Battery Electrolyte. The Journal of Physical Chemistry C 2012, 116 (28), 14764-14771. 